\title{
Erratum to: Quantifying the legacy of the Chinese Neolithic on the maternal genetic heritage of Taiwan and Island Southeast Asia
}

\author{
Andreia Brandão ${ }^{1,2,3,4} \cdot$ Ken Khong Eng ${ }^{5,6} \cdot$ Teresa Rito $^{1,7,8} \cdot$ Bruno Cavadas $^{1,2}$. \\ David Bulbeck $^{9} \cdot$ Francesca Gandini $^{3} \cdot$ Maria Pala $^{3} \cdot$ Maru Mormina $^{5,10}$. \\ Bob Hudson $^{11}$ - Joyce White ${ }^{12}$ - Tsang-Ming Ko ${ }^{13}$ - Mokhtar Saidin ${ }^{6}$. \\ Zainuddin Zafarina ${ }^{14,15} \cdot$ Stephen Oppenheimer ${ }^{16}$ - Martin B. Richards ${ }^{3,5}$. \\ Luísa Pereira $^{1,2,17} \cdot$ Pedro Soares ${ }^{1,2,5,18}$
}

Published online: 4 April 2016

(C) Springer-Verlag Berlin Heidelberg 2016

\section{Erratum to: Hum Genet (2016) 135:363-376 DOI 10.1007/s00439-016-1640-3}

In the original article, one of the co-author's (Ken Khong Eng) given name has been published incorrectly. The correct given name should be Ken Khong. The original article has been corrected.

The online version of the original article can be found under doi:10.1007/s00439-016-1640-3.

Martin B. Richards

m.b.richards@hud.ac.uk

1 IPATIMUP (Institute of Molecular Pathology and Immunology of the University of Porto), Rua Dr. Roberto Frias s/n, 4200-465 Porto, Portugal

2 i3S (Instituto de Investigação e Inovação em Saúde, Universidade do Porto), 4200 Porto, Portugal

3 Department of Biological Sciences, School of Applied Sciences, University of Huddersfield Queensgate, Huddersfield HD1 3DH, UK

4 ICBAS (Instituto Ciências Biomédicas Abel Salazar), Universidade do Porto, Rua de Jorge Viterbo Ferreira n. ${ }^{\circ} 228$, 4050-313 Porto, Portugal

5 Faculty of Biological Sciences, University of Leeds, Leeds LS2 9JT, UK

6 Centre for Global Archaeological Research, Universiti Sains Malaysia, 11800 Penang, Malaysia

7 Life and Health Sciences Research Institute (ICVS), School of Health Sciences, University of Minho, Braga, Portugal

8 ICVS/3B's-PT Government Associate Laboratory, Braga/ Guimarães, Portugal

9 Department of Archaeology and Natural History, College of Asia and the Pacific, The Australian National University, Acton ACT, Canberra 2601, Australia
10 Department of Applied Social Studies, University of Winchester, Sparkford Road, Winchester SO22 4NR, UK

11 Archaeology Department, University of Sydney, New South Wales 2006, Australia

12 Department of Anthropology, University of Pennsylvania Museum, 3260 South St., Philadelphia, USA

13 Department of Obstetrics and Gynecology, National Taiwan University, Roosevelt Rd., Taipei 10617, Taiwan

14 Malaysian Institute of Pharmaceuticals and Nutraceuticals Malaysia, National Institutes of Biotechnology Malaysia, Penang, Malaysia

15 Human Identification Unit, School of Health Sciences, Health Campus, Universiti Sains Malaysia, Kelantan, Malaysia

16 School of Anthropology, Institute of Human Sciences, The Pauling Centre, University of Oxford, 58a Banbury Road, Oxford OX2 6QS, UK

17 Faculty of Medicine, University of Porto, Al. Prof. Hernâni Monteiro, 4200-319 Porto, Portugal

18 Department of Biology, CBMA (Centre of Molecular and Environmental Biology), University of Minho, Campus de Gualtar, 4710-057 Braga, Portugal 